\title{
Difference in the way of macrophage recognition of target cells depending on their apoptotic states
}

\author{
C Fujii ${ }^{1,4}$, A Shiratsuchi ${ }^{2}$, J Manaka ${ }^{1}$, S Yonehara ${ }^{3}$ and \\ Y Nakanishi, ${ }^{\star 2}$ \\ ${ }^{1}$ Graduate School of Natural Science and Technology, Kanazawa University, \\ Takara-machi, Kanazawa, Ishikawa 920-0934, Japan \\ 2 Graduate School of Medical Science, Kanazawa University, Takara-machi, \\ Kanazawa, Ishikawa 920-0934, Japan \\ 3 Institute of Virus Research, Kyoto University, Kyoto 606-8397, Japan \\ ${ }^{4}$ Current address: Cancer Research Institute, Kanazawa University, Takara- \\ machi, Kanazawa, Ishikawa 920-0934, Japan \\ * Corresponding author: Y Nakanishi, Graduate School of Medical Science, \\ Kanazawa University, 13-1 Takara-machi, Kanazawa, Ishikawa 920-0934, \\ Japan. Tel: 81-(0)76-234-4481; Fax: 81-(0)76-234-4480; \\ E-mail: nakanaka@kenroku.kanazawa-u.ac.jp
}

Received 9.3.01; revised 30.5.01; accepted 11.6.01

Edited by $\mathrm{H}$ Ichjio

\begin{abstract}
Dying cells are selectively eliminated from the organism by phagocytosis. Previous studies suggested the existence of some other phagocytosis marker(s) that function together with phosphatidylserine, the best-characterized phagocytosis marker. We obtained here a monoclonal antibody named PH2 that inhibited macrophage phagocytosis of late apoptotic or necrotic cells, but not of early apoptotic cells. On the other hand, phagocytosis of cells at any time during the process of apoptosis was inhibitable by phosphatidylserine-containing liposomes. Inhibition occurred even when target cells were preincubated with $\mathrm{PH} 2$ and separated from unbound antibodies. Moreover, PH2 bound to apoptotic cells at late stages more efficiently than to those at early stages, and it did not bind to normal cells unless their plasma membrane was permeabilized. These results suggest that the putative $\mathrm{PH} 2$ antigen is a novel phagocytosis marker that translocates to the cell surface at late stages of apoptosis, resulting in maximal recognition and engulfment by macrophages. Cell Death and Differentiation (2001) 8, 1113-1122.
\end{abstract}

Keywords: apoptosis; macrophage; monoclonal antibody; necrosis; phagocytosis; phosphatidylserine externalization

Abbreviations: ELISA, enzyme-linked immunosorbent assay; FBS, fetal bovine serum; FITC, fluorescein isothiocyanate; mAb, monoclonal antibody; NEM, N-ethylmaleimide; PBS, phosphatebuffered saline; PC, phosphatidylcholine; PMSF, phenylmethylsulfonyl fluoride; PS, phosphatidylserine

\section{Introduction}

Apoptosis or programmed cell death plays pivotal roles throughout the life of multicellular organisms. ${ }^{1-8}$ Although apoptosis is presumably constantly occurring in many places in the organism, it is difficult to cytologically and histochemically find many apoptosing cells. This is because apoptotic cells are selectively and rapidly eliminated by phagocytosis. ${ }^{9}$ Evidence has been accumulated ${ }^{10,11}$ showing that phagocytic elimination of apoptotic cells has a role in passive selfdefense mechanisms, such as the avoidance of inflammation $^{12-14}$ and autoimmune disease ${ }^{15,16}$, as well as in active self-defense mechanisms, such as the elimination of virusinfected cells ${ }^{17}$ and antigen presentation. ${ }^{18}$ The selectivity of phagocytosis of apoptotic cells is thought to be due to the specific recognition of target cells by phagocytes, most probably through binding of receptors on phagocytes to ligands or markers on apoptotic cells. A variety of molecules have been proposed as candidate markers and their receptors. ${ }^{11,19}$ The membrane phospholipid PS is the best characterized phagocytosis marker, and is considered to be involved in the phagocytosis of many kinds of apoptotic cells. ${ }^{20}$ PS is normally restricted to the inner leaflet of the membrane bilayer, and translocates to the outer leaflet upon apoptosis induction. ${ }^{20-22}$ Phagocytosis-inducing PS receptors have been identified in several kinds of phagocytes, including endothelial cells, ${ }^{23}$ testicular Sertoli cells, ${ }^{24}$ and macrophages. ${ }^{25}$

Phagocytes have been suggested to change their mechanism of recognizing apoptotic cells depending on their activation state. ${ }^{26,27}$ However, it has been unclear whether regulation of phagocyte recognition of target cells involves changes in the array of markers on the surface of apoptotic cells. We previously found that the extent of phagocytosis continued to increase even after the externalization of PS in apoptotic cells reached a maximal level. ${ }^{28,29}$ These results led us to speculate that the expression of another marker follows externalization of PS in order for cells at late stages of apoptosis to be maximally recognized and engulfed by phagocytes. In this study, we searched for such a marker making use of mAbs.

\section{Results}

PS-mediated phagocytosis of apoptotic HF1 cells

When HF1 cells, human Fas-overexpressing HeLa cells, ${ }^{28}$ were incubated with the agonistic anti-human Fas mAb $\mathrm{CH} 11,{ }^{30}$ cell viability decreased (Figure $1 \mathrm{~A}$ ) and the number of cells with externalized PS increased (Figure 1B) as the incubation proceeded. When cells were subjected to a phagocytosis assay with thioglycolate-induced mouse peritoneal macrophages, the less-viable cells were more phago- 

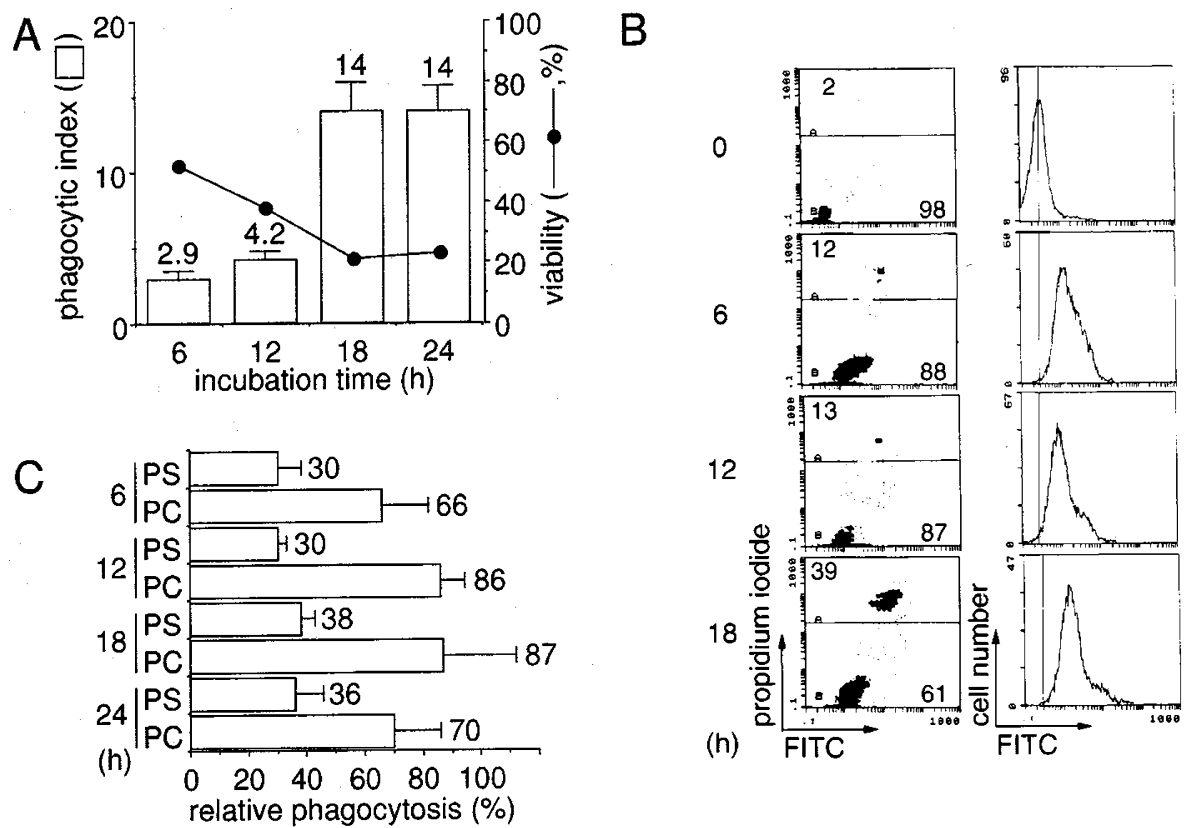

Figure 1 Macrophage phagocytosis of HF1 cells undergoing Fas-mediated apoptosis. (A) HF1 cells were treated with $\mathrm{CH} 11$ for the indicated periods and used as targets for phagocytosis by mouse peritoneal macrophages. The same cell populations were examined for viability by a dye exclusion assay with Trypan blue. The phagocytic index and viability at time 0 were $0.16-1.8$ and $96-100 \%$, respectively. (B) CH11-treated HF1 cells were analyzed for PS externalization by flow cytometry. The right panels show the binding of FITC-annexin $\mathrm{V}$ to cells less intensely stained with propidium iodide (bottom area in left panels). Numbers in the left panels indicate the relative cell number (in percentage) present in the corresponding areas. (C) Phagocytosis reactions with HF1 cells treated with $\mathrm{CH} 11$ for the indicated periods were conducted in the presence or absence of PS or PC liposomes (1 mM). The extent of phagocytosis is shown relative to that with no added liposomes, which was taken as 100

cytosed (Figure 1A). Phagocytosis of apoptotic HF1 cells at all time points was partially inhibited by liposomes containing PS, in contrast to the marginal inhibition with liposomes consisting of only PC (Figure 1C). This indicated that the phagocytosis of apoptosing HF1 cells was partially mediated by PS exposed on the surface of HF1 cells throughout the apoptosis process. However, the time courses of susceptibility to phagocytosis and PS externalization were not the same: the extent of phagocytosis continued to increase even after PS externalization reached a maximum at $6 \mathrm{~h}$. A population of cells more intensely stained with propidium iodide became significant at $18 \mathrm{~h}$ (left panels in Figure 1B). Such cells corresponded to those detached from culture dishes, as previously reported. ${ }^{28}$ We separated those floating cells from the cells remaining attached to dishes, hereafter called respectively 'detached' and 'attached' cells, at $24 \mathrm{~h}$ after apoptosis induction and used the two cell populations in a phagocytosis assay. 'Detached' cells were much better targets for macrophages than 'attached' cells (Figure 2A). Although the loss of membrane impermeability made it impossible to assess the PS externalization in 'detached' cells, phagocytosis of those cells, as well as of 'attached' cells, was apparently mediated by PS (Figure 2B). No known phagocytosis markers other than PS seemed to be involved in macrophage recognition of 'detached' cells, since neither $\mathrm{N}$-acetylglucosamine nor a peptide containing the binding sequence for integrin inhibited phagocytosis (Figure 2B). When 'attached' cells collected at various times were examined for PS externalization (Figure 2C) and their susceptibility to phagocytosis (Figure 2D), they were almost equally phagocytosed at lower efficiencies than 'detached' cells by macrophages irrespective of the amount of externalized PS. We thus concluded that the dramatic increase in the extent of phagocytosis at $18 \mathrm{~h}$ after apoptosis induction (see Figure 1A) is attributable to the appearance of 'detached' cells. From all these results, we inferred the presence of a novel phagocytosis marker on 'detached' cells, which together with PS results in the full phagocytosis of those cells by macrophages.

\section{Generation of mAb PH2, which inhibits phagocytosis of 'detached' cells}

As the first step toward identifying such a novel phagocytosis marker, we generated mAbs against 'detached' apoptotic HF1 cells and selected hybridomas producing mAbs that inhibited the phagocytosis of those cells. We finally obtained one hybridoma clone that secreted an IgM antibody. The mAb, which we named $\mathrm{PH} 2$, inhibited phagocytosis of 'detached' cells in a dose-dependent manner (Figure 3A, B), but did not influence phagocytosis of 'attached' cells (Figure $3 \mathrm{C}$ ). The effective doses of $\mathrm{PH} 2$ were within the same range as those of other monoclonal IgM clones with phagocytosis-inhibiting activity, the anti-oxidized low-density lipoprotein mAb clones EO6 and $\mathrm{EO} 12,{ }^{31}$ and the anti-human macrophage PSreceptor mAb clone $217 .^{25} \mathrm{PH} 2$ seemed to inhibit phagocytosis by binding to the target cells since 'detached' apoptotic cells became less susceptible to phagocytosis when they were preincubated with $\mathrm{PH} 2$ and separated from unbound antibodies, and this was not the case when macrophages were similarly treated (Figure 3D). 
A

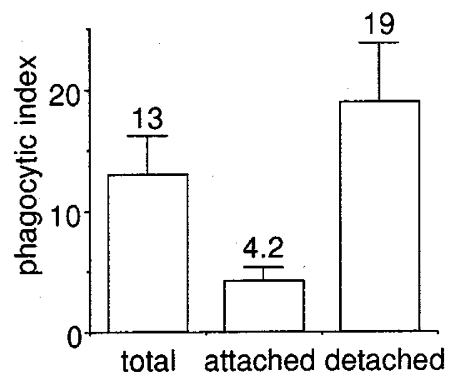

B

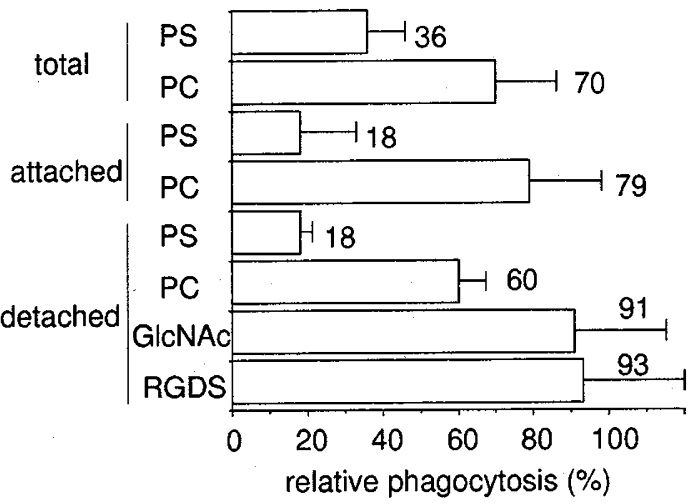

C 1

2

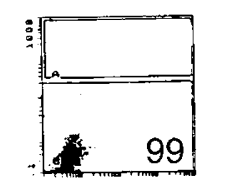

3

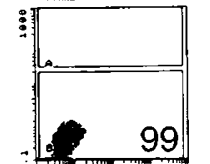

4

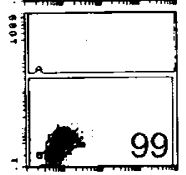

6
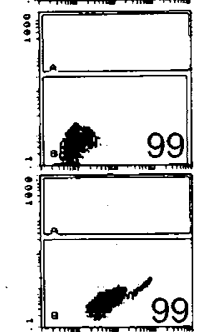

8

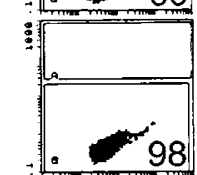

12
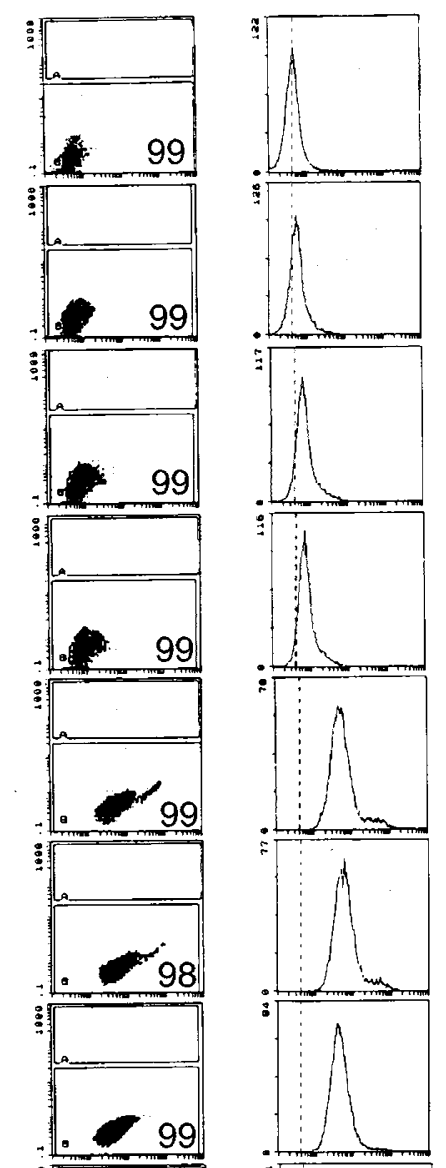

16
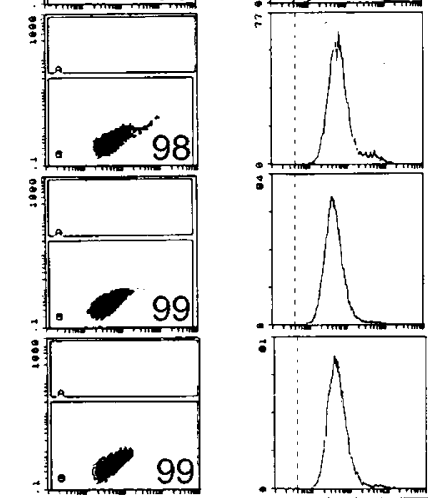

$\mathrm{D}$

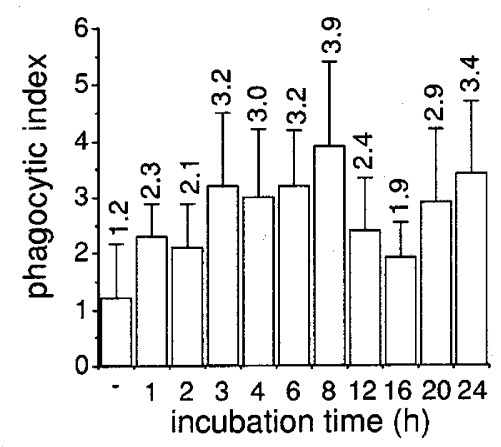

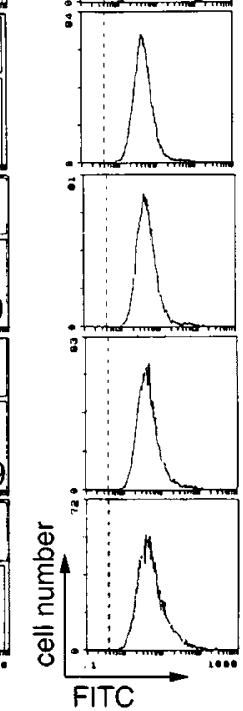

Figure 2 Phagocytosis of 'attached' and 'detached' HF1 cells. (A) HF1 cells attached to and detached from culture dishes were separated after a 24-h treatment with $\mathrm{CH} 11$ and subjected to phagocytosis assays. (B) Phagocytosis of the same cell populations as in (A) was examined in the presence or absence of liposomes (1 mM). 'Detached' HF1 cells were subjected to a phagocytosis assay in the presence or absence of phagocytosis inhibitors, $N$-acetylglucosamine (GlcNAc) $(50 \mathrm{mM})$ or a synthetic peptide containing the binding sequence for integrin (RGDS) (1 mM). The extent of phagocytosis is shown relative to that with no added inhibitors, which was taken as 100. (C) HF1 cells were incubated with $\mathrm{CH} 11$ for the indicated periods and examined for PS externalization. Numbers in the left panels indicate percentages of the cells less intensely stained with propidium iodide, which corresponded to 'attached' cells. Vertical broken lines indicate the position of the peak obtained in the analysis with normal HF1 cells. (D) 'Attached' HF1 cells were collected at various times after apoptosis induction and subjected to phagocytosis assays. The mark ' - ' indicates a cell population not treated with $\mathrm{CH} 11$

\section{Target specificity of phagocytosis inhibition by PH2}

We next examined whether $\mathrm{PH} 2$ inhibits phagocytosis of other apoptotic cells. Human leukemic Jurkat cells were induced to undergo apoptosis by two different anticancer drugs, doxorubicin and bufalin, and subjected to phagocytosis assays in the presence or absence of $\mathrm{PH} 2$. Such cells are phagocytosed by peritoneal macrophages prepared from thioglycolate-treated mice in a manner inhibitable by PS liposomes. $^{32}$ Phagocytosis of both cell populations by macrophages was clearly inhibited by $\mathrm{PH} 2$ (Figure 4A). This 


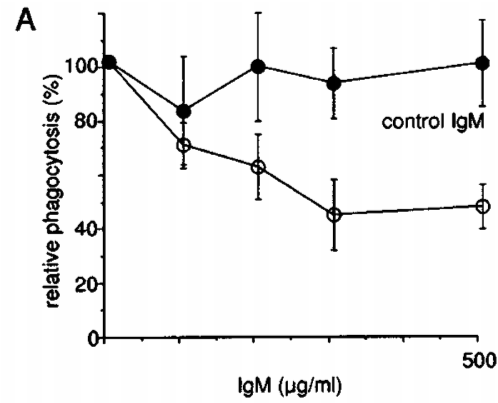

B
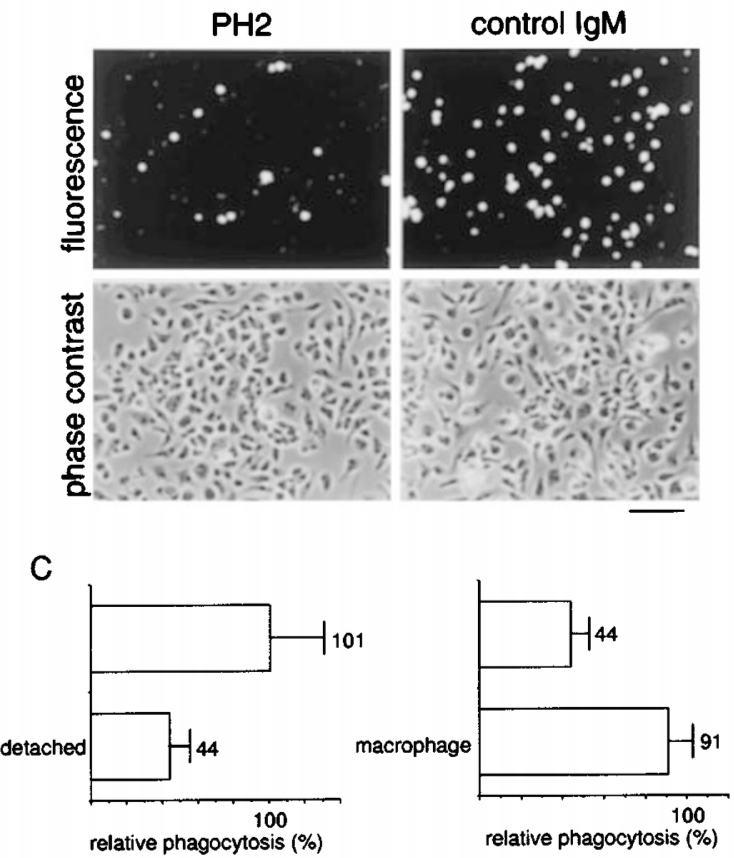

Figure 3 Effect of mAb PH2 on phagocytosis of apoptotic HF1 cells. (A) Phagocytosis reactions with 'detached' HF1 cells (at $24 \mathrm{~h}$ ) were conducted in the presence or absence of $\mathrm{PH} 2$ or control IgM, and the extent of phagocytosis is shown relative to that with no added antibody, which was taken as 100 . The mean phagocytic index in the control reaction was 20. (B) Macrophages after phagocytosis reactions in the presence of PH2 (left) or control IgM $(300 \mu \mathrm{g} / \mathrm{ml}$ ) (right) were examined under a microscope. Fluorescence signals in the top panels indicate engulfed HF1 cells, and the bottom panels show phasecontrast views of the same fields. Bar: $100 \mu \mathrm{m}$. (C) The effect of PH2 $(300 \mu \mathrm{g}$ $\mathrm{ml}$ ) on phagocytosis of 'attached' and 'detached' cells (at $24 \mathrm{~h}$ ) was examined. The extent of phagocytosis is shown relative to that with no added antibody, which was taken as 100 . The mean phagocytic indices in the control reactions were 3.6 and 26 with 'attached' and 'detached' cells, respectively. (D) 'Detached' HF1 cells (at $24 \mathrm{~h}$ ) or macrophages were preincubated with PH2 $(300 \mu \mathrm{g} / \mathrm{ml})$, removed from unbound antibodies, and subjected to phagocytosis assays. The extent of phagocytosis is shown relative to that with no antibody treatment, which was taken as 100 . The mean phagocytic index in the control reaction was 16

indicated that inhibition of phagocytosis by $\mathrm{PH} 2$ is not restricted to certain cell types or apoptotic stimuli. On the other hand, macrophage phagocytosis of latex beads and IgG-opsonized zymosan particles was not affected by $\mathrm{PH} 2$ (Figure 4B). We previously reported that treatment with NEM caused PS externalization independently of apoptosis, and that cells subjected to such treatment became susceptible to
PS-mediated phagocytosis by macrophages. ${ }^{28}$ The addition of $\mathrm{PH} 2$ did not affect phagocytosis of NEM-treated HF1 cells, whereas PS liposomes showed clear inhibition (Figure 4C). The results of these two experiments indicated that macrophage phagocytosis of non-apoptotic targets is not influenced by $\mathrm{PH} 2$. We then tested whether or not phagocytosis of necrotic cells is inhibitable by $\mathrm{PH} 2$. HF1 cells were incubated with oligomycin, an ATPase inhibitor, and analyzed for the occurrence of necrosis. Cells with permeabilized plasma membranes with no evidence of chromatin condensation, which are considered to be necrotic, ${ }^{33}$ became evident at $6 \mathrm{~h}$ after the addition of oligomycin (Figure 5A). Macrophages actively phagocytosed such cells; the mean phagocytic indices were 0.67 and 10 for cells assayed at 0 and $12 \mathrm{~h}$, respectively. Phagocytosis of the cells treated with the drug for $12 \mathrm{~h}$ was significantly inhibited in the presence of $\mathrm{PH} 2$ (Figure 5B). These results indicated that necrotic cells are phagocytosed by macrophages in a manner inhibitable by $\mathrm{PH} 2$.

In the above experiments, 'detached' cells were collected after a 24-h incubation with $\mathrm{CH} 11$. We next examined the effect of $\mathrm{PH} 2$ on phagocytosis of 'detached' cells at various times after apoptosis induction. To our surprise, the extent of inhibition of phagocytosis by $\mathrm{PH} 2$ increased as the period of incubation with $\mathrm{CH} 11$ was prolonged, and phagocytosis of the cells exposed to $\mathrm{CH} 11$ for $12 \mathrm{~h}$ or less was not influenced by $\mathrm{PH} 2$ (Figure 6A). Flow cytometric analysis was then conducted to examine the binding of the $F\left(a b^{\prime}\right)_{2}$ fragments of $\mathrm{PH} 2$ to those cell populations. The amount of bound antibody increased as the duration of apoptosis induction was prolonged (Figure $6 \mathrm{~B})$, and this coincided well with the increase in the extent of inhibition of phagocytosis by $\mathrm{PH} 2$.

The above results collectively indicate that $\mathrm{PH} 2$ inhibits macrophage phagocytosis of cells that are at late stages of apoptosis or are undergoing necrotic death.

\section{Characterization of putative PH2 antigen}

Phagocytosis of HF1 cells undergoing Fas-mediated apoptosis was inhibited by PS-containing liposomes throughout the process of apoptosis (see Figure 1C). We therefore determined the relation between PS-mediated and $\mathrm{PH} 2-$ inhibitable phagocytosis of cells detached from culture containers at late stages of apoptosis. For this purpose, PS liposomes were added to phagocytosis reactions which had been maximally inhibited by $\mathrm{PH} 2$. The results showed that the addition of liposomes brought about a further decrease in the extent of phagocytosis (Figure 7). This suggested that the two modes of phagocytosis occur independently, and that both modes contribute to the recognition and phagocytosis of late apoptotic cells by macrophages.

The presence and localization of the putative $\mathrm{PH} 2$ antigen was examined by an immunofluorescence analysis using the $F\left(a b^{\prime}\right)_{2}$ fragments of $\mathrm{PH} 2$ (Figure 8). When normal and apoptotic HF1 cells treated with $\mathrm{CH} 11$ for $24 \mathrm{~h}$ were analyzed, the antibody bound only to 'detached' apoptotic cells. The antigen appeared to be distributed outside the nucleus, and it was not clear whether it was expressed on the cell surface. As expected from the results 

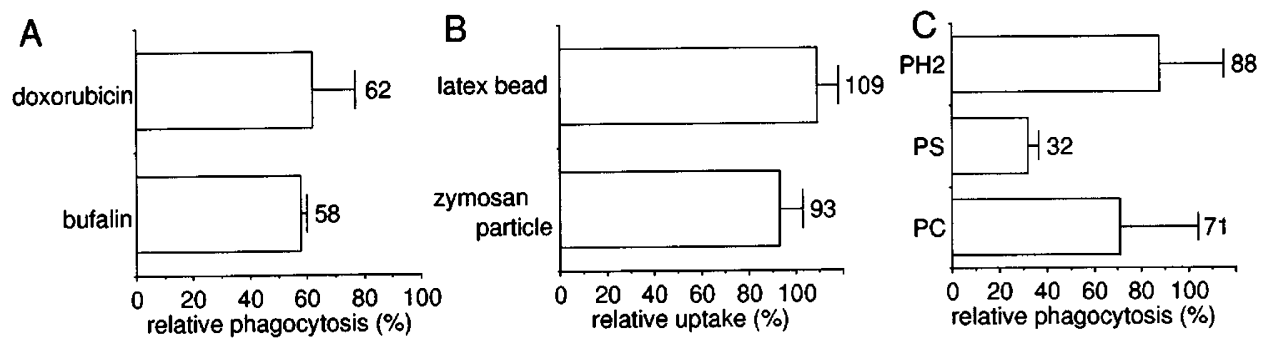

Figure 4 Effect of $\mathrm{PH} 2$ on phagocytosis of various targets. Macrophage phagocytosis was examined in the presence or absence of $\mathrm{PH} 2$ ( $300 \mu \mathrm{g} / \mathrm{ml}$ ) with various targets: (A) Jurkat cells induced to undergo apoptosis by anticancer drugs, (B) latex beads and IgG-opsonized zymosan particles, (C) NEM-treated HF1 cells. In (C), the effect of liposomes $(1 \mathrm{mM})$ was also examined. The extent of phagocytosis is shown relative to that with no added inhibitors, which was taken as 100 . The mean phagocytic indices in the control reactions were 9.1 (with doxorubicin in A), 27 (with bufalin in A), 82 (with bead in B), 91 (with zymosan in B), and 2.8 (C)

A

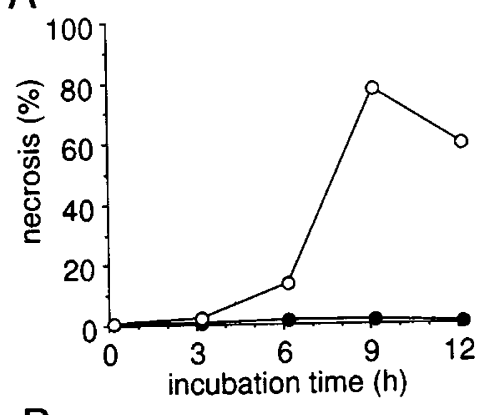

B

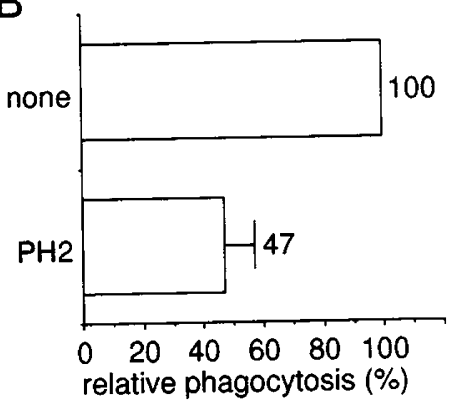

Figure 5 Effect of PH2 on phagocytosis of necrotic HF1 cells. (A) HF1 cells were incubated in the presence (open circles) or absence (closed circles) of oligomycin for the indicated periods and examined for the occurrence of necrosis. (B) Phagocytosis of oligomycin treated-HF1 cells (at $12 \mathrm{~h}$ ) was assayed in the presence or absence of $\mathrm{PH} 2(300 \mu \mathrm{g} / \mathrm{ml})$

shown in Figure 4C, NEM-treated cells were negative for the staining. Normal HF1 cells became positive when their plasma membrane was permeabilized, and confocal laser scanning microscopy showed that the antibody seemed to be partially localized in the perinuclear region. These results suggest that the putative $\mathrm{PH} 2$ antigen preexists within normal HF1 cells and translocates to the cell surface at late stages of apoptosis. However, we cannot exclude the possibility that the positive staining of 'detached' cells is partly due to internalization of the antibody since those cells were permeable to propidium iodide.

Because of the limited utility of IgM antibodies, the nature of the putative $\mathrm{PH} 2$ antigen has not been clarified at the present time. ELISA was therefore adopted to get a clue about the identity of the antigen (Figure 9). $\mathrm{PH} 2$ or its $F\left(a b^{\prime}\right)_{2}$ fragments bound efficiently to plastic containers that had been coated with total lysates of normal HF1 cells. This reaction was significantly diminished when the lysates were pretreated with trypsin or $\alpha$-chymotrypsin, but not with neuraminidase or lysozyme. The proteases lost this effect when they were heated or treated with PMSF, a serineprotease inhibitor, before they were added to the lysates. Similarly, fluorescence signals in permeabilized HF1 cells significantly decreased when the cells were treated with $\alpha$ chymotrypsin before the addition of the $F\left(a b^{\prime}\right)_{2}$ fragments of $\mathrm{PH} 2$ (Figure 10A). This effect was again abrogated by PMSF (Figure 10B). These results indicate that the antigenicity of the putative $\mathrm{PH} 2$ antigen was sensitive to digestion with proteases.

\section{Discussion}

A variety of molecules have been proposed as phagocytosis markers and their receptors. ${ }^{11,19}$ One possible explanation for such diversity might be that distinct populations of apoptotic cells and phagocytes possess distinct markers and receptors, respectively. Another could be that simultaneous usage of multiple recognition systems should help apoptotic cells be more effectively and rapidly eliminated. Previous reports have shown that macrophages utilize distinct sets of phagocytosis receptors depending on their activation states. ${ }^{26,27}$ However, it has not been clear whether dying cells express differing phagocytosis markers depending on their stage in apoptosis. Here we have suggested that apoptosing cells express an additional phagocytosis marker at later stages and become more susceptible to macrophage phagocytosis. We obtained a mAb that inhibits phagocytosis of cells at late but not early stages of apoptosis. Since the mAb, named $\mathrm{PH} 2$, bound to normal or early apoptotic cells to only small extents, the cognate antigen is likely to appear on the cell surface at later stages of apoptosis. Phagocytosis of these cells was not affected by inhibitors for known phagocytosis markers except for PS, and was additively inhibited by PS liposomes and $\mathrm{PH} 2$. These results strongly suggest that the $\mathrm{PH} 2$ antigen is a novel phagocytosis marker which is expressed on the surface of late apoptotic cells and contributes together with PS to the efficient recognition of those cells by macrophages. 

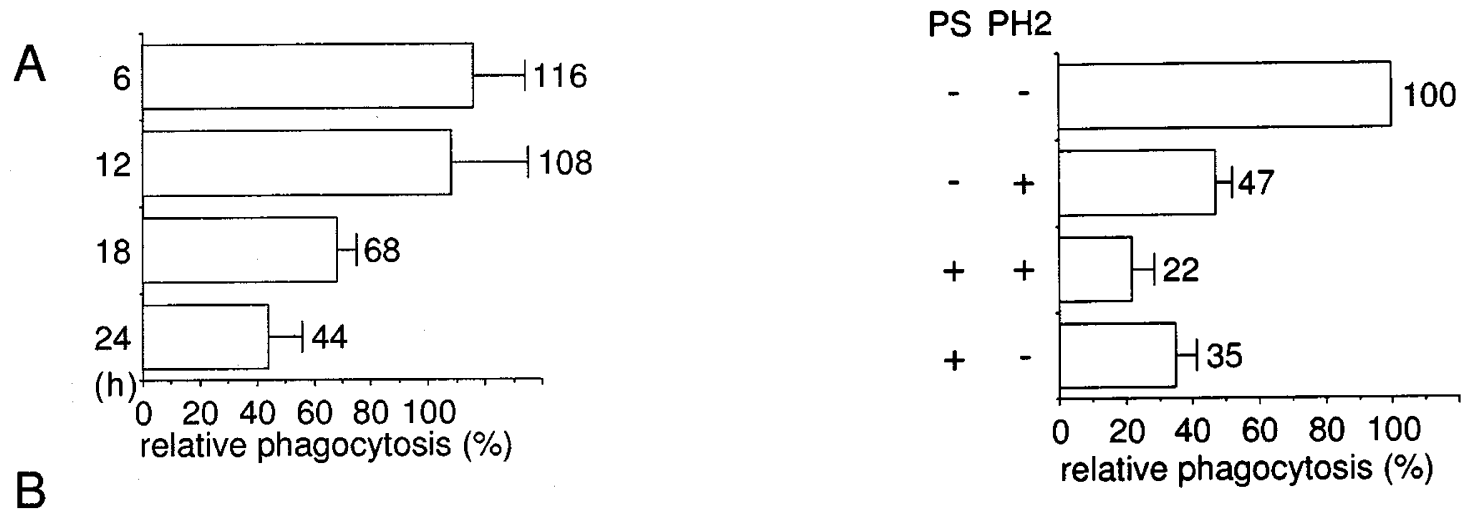

Figure 7 Additive effect of PH2 and PS liposomes on phagocytosis. Phagocytosis reactions with 'detached' HF1 cells (at $24 \mathrm{~h}$ ) were conducted in the presence or absence of PS liposomes $(0.2 \mathrm{mM})$, PH2 $(300 \mu \mathrm{g} / \mathrm{ml})$, or their combination. The mean phagocytic index in the control reaction was 22

6

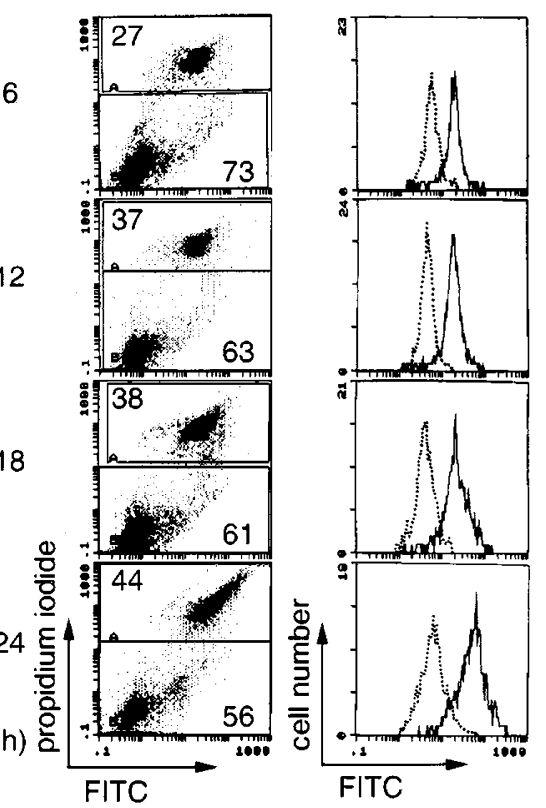

Figure 6 Effect of PH2 on phagocytosis of 'detached' HF1 cells at various stages of apoptosis. (A) 'Detached' HF1 cells were collected at the indicated times after $\mathrm{CH} 11$ addition and subjected to phagocytosis assays in the presence or absence of $\mathrm{PH} 2(300 \mu \mathrm{g} / \mathrm{ml})$. The extent of phagocytosis is shown relative to that with no added antibody, which was taken as 100 . The mean phagocytic indices in the control reactions were $14(6 \mathrm{~h}), 15(12 \mathrm{~h}), 18(18 \mathrm{~h})$, and $26(24 \mathrm{~h})$. Phagocytic indices with 'detached' cells treated with $\mathrm{CH} 11$ for less than $6 \mathrm{~h}$ were too small to determine the effect of PH2. (B) HF1 cells treated with $\mathrm{CH} 11$ for the indicated periods were incubated with propidium iodide and the biotinylated $\mathrm{F}\left(\mathrm{ab} \mathrm{b}^{\prime}\right)_{2}$ fragments of $\mathrm{PH} 2$, supplemented with FITCconjugated avidin, and analyzed by flow cytometry. Right panels show binding of the antibody to cells more intensely stained with propidium iodide (top area in the left panels), which corresponded to 'detached' cells. Broken lines indicate the results from control experiments using the unlabeled antibody

The execution of apoptosis does not require the activation of gene expression. ${ }^{34}$ Most factors needed for this process are produced by the modification of preexisting molecules, for example, through the cascade of proteolytic activation of caspases. ${ }^{34}$ Phagocytosis markers, on the other hand, may be produced without structurally modifying any molecules. Since phagocytosis markers should function on the surface of apoptosing cells, any molecules that exist exclusively inside of normal cells could become such markers simply by being transferred to the cell surface

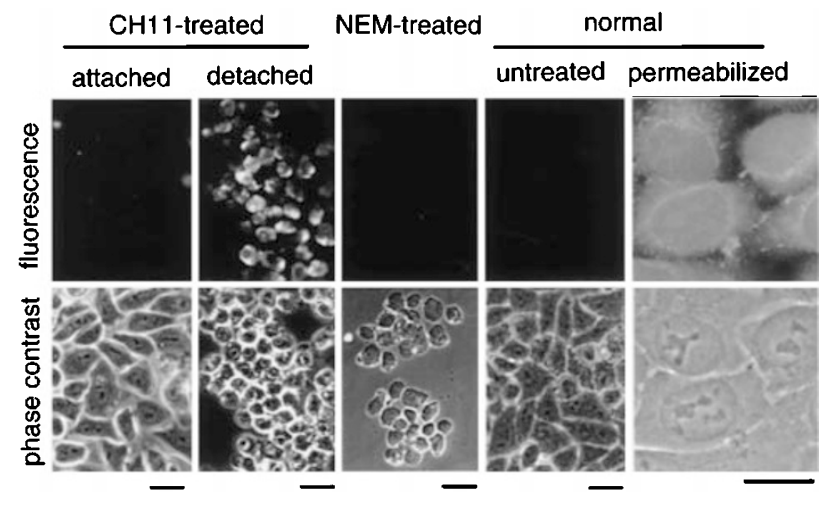

Figure 8 Immunofluorescence analysis of HF1 cells with PH2. Binding of the antibody was examined with 'attached' and 'detached' cells treated with $\mathrm{CH} 11$ for $24 \mathrm{~h}$, NEM-treated cells, and normal cells. The cells were incubated with the biotinylated $\mathrm{F}\left(\mathrm{ab} \mathrm{b}_{2}\right)_{2}$ fragments of $\mathrm{PH} 2$, supplemented with FITC-avidin, and examined under a fluorescence microscope. Fluorescence and phasecontrast views of the same fields are shown. Normal HF1 cells with permeabilized plasma membranes were similarly analyzed by confocal laser scanning microscopy. Bar: $10 \mu \mathrm{m}$

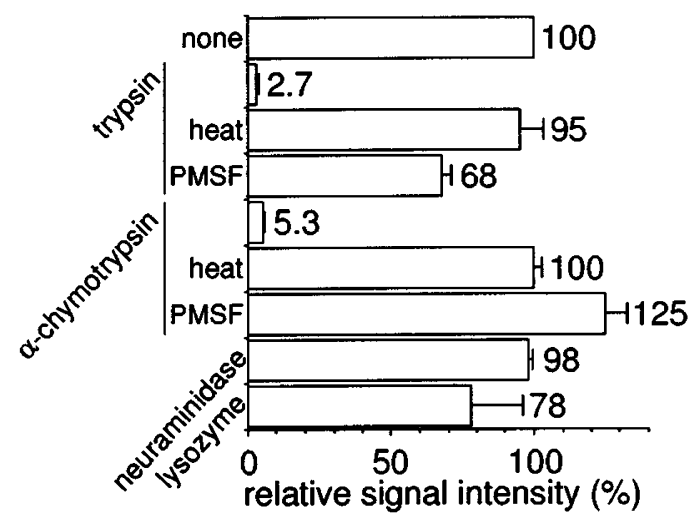

Figure 9 ELISA of putative PH2 antigen. Total lysates of normal HF1 cells were treated with the indicated degradative enzymes, plated, and reacted with $\mathrm{PH}$ 2. Signal intensities are presented relative to that in the control reaction with no enzyme treatment 

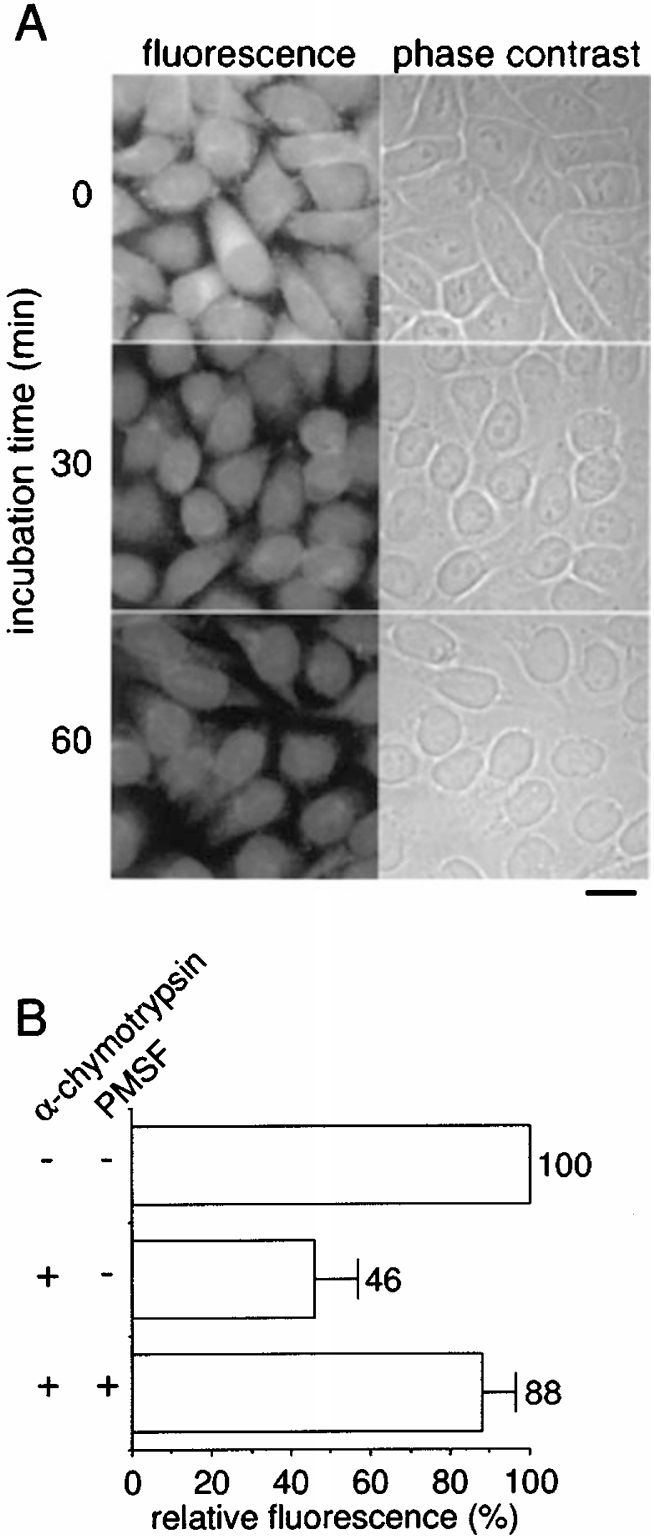

Figure 10 Effect of protease on immunofluorescence detection of putative $\mathrm{PH} 2$ antigen. (A) Permeabilized HF1 cells were incubated with $\alpha$-chymotrypsin for the indicated periods and analyzed for the binding of the $F\left(a b^{\prime}\right)_{2}$ fragments of $\mathrm{PH} 2$ by confocal laser scanning microscopy. Bar: $10 \mu \mathrm{m}$. (B) The cells were treated with $\alpha$-chymotrypsin for $30 \mathrm{~min}$ in the presence or absence of PMSF and analyzed as in (A). Intensities of the fluorescence signals were determined digitally and are presented relative to that in the control reaction

during apoptosis. One such case is the best-characterized phagocytosis marker, PS, a phospholipid that is restricted to the inner leaflet of the membrane bilayer in normal cells, but translocates to the outer leaflet and is exposed to the cell surface upon apoptosis induction. ${ }^{20-22}$ Normal cells became positive for the binding of the $F\left(a b^{\prime}\right)_{2}$ fragments of $\mathrm{PH} 2$ when their plasma membrane was permeabilized. This indicated that the putative $\mathrm{PH} 2$ antigen preexists in normal cells. It is thus likely that the novel phagocytosis marker proposed here has a mode of surface expression similar to that of PS. The identity of the $\mathrm{PH} 2$ antigen is unclear at present. ELISA and immunofluorescence analyses indicated that the antigenicity of the putative $\mathrm{PH} 2$ antigen is sensitive to protease digestion. This suggests that the antigen is a protein or some molecule associated with protein, and together with the observation that the perinuclear region gave relatively intense signals in immunofluorescence analysis of permeabilized normal cells, suggests that the $\mathrm{PH} 2$ antigen is a protein associated with the membranous apparatus.

Cells undergoing necrosis are actively engulfed by phagocytes. $^{35-38}$ Like phagocytosis of apoptotic cells, phagocytosis of necrotic cells is likely to be involved in both passive and active self-defense mechanisms. A few reports indicated that the phagocytosis of necrotic cells is more important for the cross-presentation of antigens by dendritic cells than that of apoptotic cells. ${ }^{35,36}$ The mode of cell-cell recognition in macrophage phagocytosis of necrotic cells is still unknown. Apoptotic cells often become necrotic when they are left undigested for a long period. If such necrotic cells retain phagocytosis markers that are expressed on their surface during the process of apoptosis, they should still be good targets for phagocytosis. Our results showed that the putative $\mathrm{PH} 2$ antigen serves as a marker for the recognition of not only apoptotic but also necrotic cells by macrophages. Since oligomycin-treated cells did not undergo apoptosis, the inhibition of the phagocytosis of those cells by $\mathrm{PH} 2$ cannot be attributed to a phagocytosis marker that was carried over from the apoptotic state. Furthermore, the phagocytosis of some necrotic cells appeared to be mediated by PS (our unpublished observations). These results suggest that there may be a similar mechanism for surface expression of phagocytosis markers in cells dying by apoptosis and necrosis.

\section{Materials and Methods}

\section{Cell culture and induction of cell death}

HF1 cells were maintained in minimum essential medium (Nissui Pharmaceutical, Tokyo, Japan) supplemented with $10 \%$ FBS at $37^{\circ} \mathrm{C}$ in a humidified atmosphere of $5 \% \mathrm{CO}_{2}$ in air, and were induced to undergo apoptosis by addition of $\mathrm{CH} 11(0.5 \mu \mathrm{g} / \mathrm{ml})$ (MBL, Nagoya, Japan) as described previously. ${ }^{28}$ To prepare the apoptosing cells used for screening hybridomas, HF1 cells were simultaneously treated with $\mathrm{CH} 11(10 \mathrm{ng} / \mathrm{ml})$ and cycloheximide $(50 \mu \mathrm{g} / \mathrm{ml})$ for $24 \mathrm{~h}$. After apoptosis induction, cells detached from or remaining attached to culture dishes were separately recovered and used in experiments. Both of these 'detached' and 'attached' cell populations were considered to be apoptotic since they possessed condensed chromatin. HF1 cells were treated with NEM $(1 \mathrm{mM})$ at $37^{\circ} \mathrm{C}$ for $6 \mathrm{~min}$ to induce apoptosis-independent PS externalization as described previously. ${ }^{28}$ The occurrence of chromatin condensation was assessed by staining cells with Hoechst 33342 followed by examination under a fluorescence/phase-contrast microscope (BX-50; Olympus, Tokyo, Japan). PS externalization was assessed by measuring the binding of FITC-labeled annexin V (Bender MedSystems, Vienna, Austria) using a flow cytometer (EPICS-XL; Coulter, FL, USA) as described previously. ${ }^{39,40}$ Briefly, cells were treated with 
FITC-annexin V and propidium iodide, and cells less intensely stained with propidium iodide were gated and analyzed for the binding of FITCannexin V. To induce necrosis, HF1 cells were cultured in glucose-free Dulbecco's modified Eagle's medium (Sigma, St. Louis, MO, USA) with $10 \%$ FBS in the presence of oligomycin $(10 \mu \mathrm{M})\left(\right.$ Sigma) ${ }^{41}$ The cells were simultaneously stained with propidium iodide and Hoechst 33342, and examined under a fluorescence microscope. Both are DNA-binding fluorescent dyes, and the former was used to evaluate the permeabilization of the plasma membrane, and the latter to analyze chromatin condensation. Cells positively stained by propidium iodide with no condensed chromatin were considered to be necrotic. ${ }^{33}$ Jurkat cells, a human leukemic T-cell line, were grown in RPMI 1640 medium (Nissui Pharmaceuticals) with 10\% FBS. For induction of apoptosis, they were incubated with doxorubicin (Sigma) $(0.3 \mu \mathrm{g} / \mathrm{ml})$ for $36 \mathrm{~h}$ or with bufalin (Sigma) $\left(10^{-7} \mathrm{M}\right)$ for $24 \mathrm{~h}$ as described previously. ${ }^{32}$

\section{Macrophage preparation and phagocytosis assay}

Macrophages were prepared from the peritoneal fluids of thioglycolateinjected BDF $_{1}$ mice (female, 8-12 weeks old) and cultivated on coverslips until use as described previously. ${ }^{28}$ The phagocytosis assay was performed essentially as described. ${ }^{28,42}$ Briefly, target cells were labeled with biotin, mixed with macrophages (at a ratio of 10 target cells to one macrophage), and incubated at $37^{\circ} \mathrm{C}$ for $2 \mathrm{~h}$. The mixture was treated with trypsin to remove target cells free from or lightly attached to macrophages. The remaining macrophages were then fixed, permeabilized, and supplemented with FITC-conjugated avidin. The number of macrophages that had engulfed apoptotic cells was determined by examination under a fluorescence/phase-contrast microscope and expressed relative to the total number of macrophages taken as 100 , and termed the phagocytic index. The mean and standard deviation of a typical example from at least three independent experiments are presented. To examine the effects of mAbs, apoptotic HF1 cells were preincubated with the culture medium of hybridomas or purified mAbs at $4^{\circ} \mathrm{C}$ for $30 \mathrm{~min}$ and subsequently used as the target cells in a phagocytosis assay unless otherwise stated. A mouse myeloma IgM (Calbiochem, La Jolla, CA, USA) was used as a control antibody. Liposomes, peptides, and sugars were directly added to phagocytosis reactions and their effects were determined. Liposomes composed of either PC only (PC liposomes) or a combination of PC and PS at a ratio of 7:3 (PS liposomes) were prepared as described previously. ${ }^{42}$ The synthetic peptide H-Gly-Arg-Gly-Asp-Ser-Pro-Lys-OH was purchased from Bachem Feinchemikalien AG (Bubendrof, Switzerland).

\section{Incorporation of latex beads and zymosan particles by macrophages}

Macrophages were incubated with fluorescence-labeled latex beads (Polysciences, Warrington, PA, USA) at $37^{\circ} \mathrm{C}$ for $1 \mathrm{~h}$, washed with PBS, fixed with paraformaldehyde, and analyzed by fluorescence microscopy. Incorporation of zymosan particles was examined as described previously. ${ }^{29}$ In brief, macrophages were incubated with fluorescence-labeled, mouse IgG-opsonized zymosan particles (Sigma) and examined under a fluorescence microscope. The extent of incorporation of latex beads and zymosan particles was determined as described for the phagocytic index.

\section{Generation and purification of mAbs}

Ten million HF1 cells were detached from culture dishes after a 24-h incubation with $\mathrm{CH} 11$ and emulsified with complete Freund's adjuvant
(Sigma), and the emulsion was inoculated intraperitoneally into Balb/c mice (female, 6 weeks old). After three serial immunizations, spleen cells were fused with the Balb/c-derived myeloma cell line SP-2. The resulting hybridomas were maintained in RPMI 1640 medium containing $15 \% \mathrm{FBS}$ at $37^{\circ} \mathrm{C}$ in $7 \% \mathrm{CO}_{2}$ in air, and the culture media were screened for inhibition of phagocytosis of 'detached' HF1 cells. Hybridomas that showed inhibitory activity were further cultured and subjected to cloning. The class and subclass of mAbs were determined using a Mouse MonoAB ID/SP Kit (Zymed Laboratories, San Francisco, CA, USA). Ascites fluid was collected from Balb/c mice (male, 6 weeks old), which had been primed with 2,6,10,14tetramethylpentadecane (Aldrich, Milwaukee, WI, USA) and inoculated with $1 \times 10^{7}$ cloned hybridoma cells. A monoclonal IgM antibody, which we named $\mathrm{PH} 2$, was purified from the ascites fluid using Ultralink immobilized mannan binding protein (Pierce, Rockford, IL, USA). For preparation of the $\mathrm{F}\left(\mathrm{ab}^{\prime}\right)_{2}$ fragments, $\mathrm{PH} 2$ was partially purified from the ascites fluid by ammonium sulfate $(50 \%)$ precipitation and cleaved by pepsin (Sigma) in a citrate buffer $(\mathrm{pH} 4.2)$. The generated $F\left(a b^{\prime}\right)_{2}$ fragments were purified to homogeneity by gel filtration using Sephacryl S-300 (Amersham Pharmacia Biotech, Uppsala, Sweden).

\section{Flow cytometry and immunofluorescence}

To examine the antibody binding by flow cytometry, cells were incubated with either the biotin-labeled or unlabeled $F\left(a b^{\prime}\right)_{2}$ fragments of $\mathrm{PH} 2(250 \mu \mathrm{g} / \mathrm{ml})$, supplemented with FITC-avidin, and analyzed in a flow cytometer. For immunofluorescence, normal cells and 'attached' cells were grown on Lab-Tec chamber slides (Nalge Nunc International, Tokyo, Japan), and 'detached' cells and NEM-treated cells were smeared on 3-aminopropyltriethoxysilane-coated slide glasses. For preparation of plasma membrane-permeabilized cells, normal HF1 cells attached to the chamber slides were treated with a solution consisting of $2 \%$ paraformaldehyde $/ 0.1 \%$ glutaraldehyde/ $0.05 \%$ Triton $\mathrm{X}-100$, and then with methanol for $10 \mathrm{~min}$ at room temperature. All the cell samples were washed with PBS containing bovine serum albumin, mixed with the biotin-labeled $F\left(a b^{\prime}\right)_{2}$ fragments $(1 \mathrm{mg} / \mathrm{ml})$, supplemented with FITC-avidin, and examined under a fluorescence microscope or a confocal laser scanning microscope (LSM510; Carl Zeiss, Jena, Germany). To examine the effect of proteases, permeabilized HF1 cell samples were incubated with $\alpha$ chymotrypsin (Sigma) $(10 \mu \mathrm{g} / \mathrm{ml})$ at $37^{\circ} \mathrm{C}$ in the presence or absence of PMSF (Sigma) (1 $\mathrm{mM}$ ) prior to the antibody addition.

\section{ELISA}

Normal HF1 cells were suspended in a buffer consisting of $1 \%$ Nonidet P-40/0.1\% sodium deoxycholate/0.1\% sodium dodecyl sulfate/ $0.15 \mathrm{M}$ $\mathrm{NaCl} / 10 \mathrm{mM}$ Tris- $\mathrm{HCl}, \mathrm{pH} 7.4$, sonicated briefly, and incubated at $4{ }^{\circ} \mathrm{C}$ for $30 \mathrm{~min}$ with gentle agitation. They were then supplemented with dithiothreitol $(10 \mathrm{mM})$ and centrifuged. The supernatants were transferred into multi-well containers $(1.25 \mu \mathrm{g}$ protein per well), and incubated at $4^{\circ} \mathrm{C}$ overnight. The samples were aspirated, and the container was filled with FBS and kept at $37^{\circ} \mathrm{C}$ for $90 \mathrm{~min}$. The containers were washed, supplemented with $\mathrm{PH} 2(5 \mu \mathrm{g} / \mathrm{ml})$, and incubated at $37^{\circ} \mathrm{C}$ for $90 \mathrm{~min}$. The wells were then washed and reacted with a peroxidase-labeled anti-mouse IgM antibody (Jackson ImmunoResearch Laboratories, West Grove, PA, USA) at $37^{\circ} \mathrm{C}$ for $90 \mathrm{~min}$. The amount of bound secondary antibody was determined by a colorimetric reaction with o-phenylene diamine. To examine the effect of degradative enzymes, cell lysates were incubated with 1tosylamido-2-phenylethyl chloromethyl ketone-treated trypsin $(10 \mu \mathrm{g} /$ 
$\mathrm{ml})$, $\alpha$-chymotrypsin $(100 \mu \mathrm{g} / \mathrm{ml})$, neuraminidase $(0.1$ units $/ \mathrm{ml})$, or lysozyme $(1 \mathrm{mg} / \mathrm{ml})$ at $30^{\circ} \mathrm{C}$ for $1 \mathrm{~h}$, heated at $100^{\circ} \mathrm{C}$ for $10 \mathrm{~min}$ to inactivate the enzymes, and subjected to the ELISA procedure. Protease treatments were also conducted in the presence of PMSF $(1 \mathrm{mM})$ or with enzymes that had been pre-heated at $100^{\circ} \mathrm{C}$ for $10 \mathrm{~min}$. A typical example from three independent experiments with similar results is presented.

\section{Acknowledgements}

We thank Kazushi Iwata and Fuji Chemical Industries, Ltd. for help in generating mAbs, Yoshihide Tsujimoto and Nobuo Hanai for suggestions on necrosis induction and ELISA, respectively, and Valerie Fadok for critically reading the manuscript. This study was supported by Grant-inAid for Scientific Research from the Japan Society for the Promotion of Science, a grant from the Organized Research Combination System of the Science and Technology Agency of Japan, and a grant from the Sumitomo Foundation.

\section{References}

1. Cohen JJ (1991) Programmed cell death in the immune system. Adv. Immunol. 50: $55-85$

2. Ellis RE, Yuan J and Horvitz HR (1991) Mechanism and functions of cell death. Annu. Rev. Cell Biol. 7: 663-698

3. Raff MC (1992) Social controls on cell survival and cell death. Nature 356: $397-$ 400

4. Thompson CB (1995) Apoptosis in the pathogenesis and treatment of disease. Science 267: 1456- 1462

5. Dunkel L, Hirvonen V and Erkkilä K (1997) Clinical aspects of male germ cell apoptosis during testis development and spermatogenesis. Cell Death Differ. 4: $171-179$

6. Jacobson MD, Weil M and Raff MC (1997) Programmed cell death in animal development. Cell 88: 347-354

7. Marti A, Jaggi R, Vallan C, Ritter PM, Baltzer A, Srinivasan A, Dharmarajan AM and Friis RR (1999) Physiological apoptosis in hormone-dependent tissues: involvement of caspases. Cell Death Differ. 6: 1190-1200

8. Vaux DL and Korsmeyer SJ (1999) Cell death in development. Cell 96: 245-254

9. Wyllie AH, Kerr JFR and Currie AR (1980) Cell death: the significance of apoptosis. Int. Rev. Cytol. 68: 251-306

10. Ren Y and Savill J (1998) Apoptosis: the importance of being eaten. Cell Death Differ. 5: $563-568$

11. Savill J and FadokV (2000) Corpse clearance defines the meaning of cell death. Nature 407: 784-788

12. Voll RE, Herrmann M, Roth EA, Stach C and Kalden JR (1997) Immunosuppressive effects of apoptotic cells. Nature 390: 350-351

13. Fadok VA, Bratton DL, Konowal A, Freed PW, Westcott JY and Henson PM (1998) Macrophages that have ingested apoptotic cells in vitro inhibit proinflammatory cytokine production through autocrine/paracrine mechanisms involving TGF- $\beta$, PGE2, and PAF. J. Clin. Invest. 101: 890-898

14. McDonald PP, Fadok VA, Bratton D and Henson PM (1999) Transcriptional and translational regulation of inflammatory mediator production by endogenous TGF- $\beta$ in macrophages that have ingested apoptotic cells. J. Immunol. 163: $6164-6172$

15. Botto M, Dell'Agnola C, Bygrave AE, Thompson EM, Cook HT, Petry F, Loos M, Pandolfi PP and Walport MJ (1998.) Homozygous Clq deficiency causes glomerulonephritis associated with multiple apoptotic bodies. Nat. Genet. 19: $56-59$

16. Taylor PR, Carugati A, Fadok VA, Cook HT, Andrews M, Carroll MC, Savill JS, Henson PM, Botto M and Walport MJ (2000) A hierarchical role for classical pathway complement proteins in the clearance of apoptotic cells in vivo. J. Exp. Med. 192: $359-366$
17. Fujimoto I, Pan J, Takizawa T and Nakanishi Y (2000) Virus clearance through apoptosis-dependent phagocytosis of influenza A virus-infected cells by macrophages. J. Virol. 74: 3399-3403

18. Steinman RM, Turley S, Mellman I and Inaba K (2000) The induction of tolerance by dendritic cells that have captured apoptotic cells. J. Exp. Med. 191:411-416

19. Savill J (1997) Recognition and phagocytosis of cells undergoing apoptosis. Brit. Med. Bull. 53: 491-508

20. Fadok VA, Bratton DL, Frasch SC, Warner ML and Henson PM (1998) The role of phosphatidylserine in recognition of apoptotic cells by phagocytes. Cell Death Differ. 5: 551-562

21. Williamson $P$ and Schlegel RA (1994) Back and forth: the regulation and function of transbilayer phospholipid movement in eukaryotic cells (Review). Mol. Membr. Biol. 11: 199-216

22. Zwaal RFA and Schroit AJ (1997) Pathophysiologic implications of membrane phospholipid asymmetry in blood cells. Blood 89: 1121-1132

23. Oka K, Sawamura T, Kikuta K, Itokawa S, Kume N, Kita T and Masaki T (1998) Lectin-like oxidized low-density lipoprotein receptor 1 mediates phagocytosis of aged/apoptotic cells in endothelial cells. Proc. Natl. Acad. Sci. USA 95: 95359540

24. Shiratsuchi A, Kawasaki Y, Ikemoto M, Arai $\mathrm{H}$ and Nakanishi $Y$ (1999) Role of class $B$ scavenger receptor type I in phagocytosis of apoptotic rat spermatogenic cells by Sertoli cells. J. Biol. Chem. 274: 5901-5908

25. Fadok VA, Bratton DL, Rose DM, Pearson A, Ezekewitz RAB and Henson PM (2000) A receptor for phosphatidylserine-specific clearance of apoptotic cells. Nature 405: 85-90

26. Pradhan D, Krahling S, Williamson P and Schlegel RA (1997) Multiple systems for recognition of apoptotic lymphocytes by macrophages. Mol. Biol. Cell 8: 767778

27. Fadok VA, Warner ML, Bratton DL and Henson PM (1998) CD36 is required for phagocytosis of apoptotic cells by human macrophages that use either a phosphatidylserine receptor or the vitronectin receptor $\left(\alpha_{v} \beta_{3}\right)$. J. Immunol. 161: $6250-6257$

28. Shiratsuchi A, Osada S, Kanazawa S and Nakanishi Y (1998) Essential role of phosphatidylserine externalization in apoptosing cell phagocytosis by macrophages. Biochem. Biophys. Res. Commun. 246: 549-555

29. Shiratsuchi A, Kaido M, Takizawa T and Nakanishi Y (2000) Phosphatidylserinemediated phagocytosis of influenza A virus-infected cells by mouse peritoneal macrophages. J. Virol. 74: 9240-9244

30. Yonehara S, Ishii A and Yonehara M (1989) A cell-killing monoclonal antibody (anti-Fas) to a cell surface antigen codownregulated with the receptor of tumor necrosis factor. J. Exp. Med. 169: 1747-1756

31. Chang M-K, Bergmark C, Laurila A, Hörkkö S, Han K-H, Friedman P, Dennis EA and Witztum JL (1999) Monoclonal antibodies against oxidized low-density lipoprotein bind to apoptotic cells and inhibit their phagocytosis by elicited macrophages: Evidence that oxidation-specific epitopes mediate macrophage recognition. Proc. Natl. Acad. Sci. USA 96: 6353-6358

32. Shiratsuchi A and Nakanishi Y (1999) Phosphatidylserine-mediated phagocytosis of anticancer drug-treated cells by macrophages. J. Biochem. 126: 11011106

33. Shimizu S, Eguchi Y, Kamiike W, Itoh Y, Hasegawa J, Yamabe K, Otsuki Y, Matsuda $\mathrm{H}$ and Tsujimoto $Y(1996)$ Induction of apoptosis as well as necrosis by hypoxia and predominant prevention of apoptosis by $\mathrm{Bcl}-2$ and $\mathrm{Bcl}-\mathrm{X}_{\mathrm{L}}$. Cancer Res. 56: 2161-2166

34. Hengartner MO (2000) The biochemistry of apoptosis. Nature 407: 770-776

35. Gallucci S, Lolkema M and Matzinger P (1999) Natural adjuvants: Endogenous activators of dendritic cells. Nat. Med. 5: 1249-1255

36. SauterB, AlbertML, Francisco L, Larsson M, Somersan Sand Bhardwaj N (2000) Consequences of cell death: Exposure to necrotic tumor cells, but not primary tissue cells or apoptotic cells, induces the maturation of immunostimulatory dendritic cells. J. Exp. Med. 191: 423-433

37. Hirt UA, Gantner F and Leist M (2000) Phagocytosis of nonapoptotic cells dying by caspase-independent mechanisms. J. Immunol. 164: 6520-6529

38. Subklewe M, Paludan C, Tsang ML, Mahnke K, Steinman RM and Münz C (2001) Dendritic cells cross-present latency gene products from Epstein-Barr virustransformed $\mathrm{B}$ cells and expand tumorreactive $\mathrm{CD} 8^{+}$killer T cells. J. Exp. Med. 193: $405-411$ 
39. Koopman G, Reutelingsperger CPM, Kuijten GAM, Keehnen RMJ, Pals ST and van Oers MHJ (1994) Annexin V for flow cytometric detection of phosphatidylserine expression on B cells undergoing apoptosis. Blood 84: $1415-1420$

40. Martin SJ, Reutelingsperger CPM and Green DR (1996) Annexin V: a specific probe for apoptotic cells. In Techniques in apoptosis: A user's guide, Cotten YG and Martin SJ, eds (London: Portland Press) pp. 107-119
41. Eguchi Y, Shimizu S and Tsujimoto Y (1997) Intracellular ATP levels determine cell death fate by apoptosis or necrosis. Cancer Res. 57: 1835-1840

42. Shiratsuchi A, Umeda M, Ohba Y and Nakanishi Y (1997) Recognition of phosphatidylserine on the surface of apoptotic spermatogenic cells and subsequent phagocytosis by Sertoli cells of the rat. J. Biol. Chem. 272: 2354 2358 